\title{
A VIOLÊNCIA LABORAL E O JULGAMENTO EM UMA PERSPECTIVA DE GÊNERO
}

\section{LABOR VIOLENCE AND JUDGING FROM A GENDER PERSPECTIVE}

\author{
Carolina Kemmelemeier ${ }^{1}$ \\ Universidade Estadual do Oeste do Paraná (Unioeste) \\ Olívia de Quintana Figueiredo Pasqualeto ${ }^{2}$ \\ Universidade de São Paulo (USP)
}

\begin{abstract}
Resumo:
O artigo tem como objeto central o dever estatal de eliminação da violência laboral e sua articulação com o julgamento em perspectiva de gênero na esfera trabalhista. Esse enfoque foi selecionado por permitir contextualizar e compreender a evolução da produção teórica e normativa sobre gênero, trabalho e violência e a interface entre Direito do Trabalho e Direitos Humanos. Para tanto, sua elaboração teve como pergunta estruturante: Quais são os potenciais contribuições da Convenção 190 da Organização Internacional do Trabalho (OIT) para a transformação da teoria da decisão judicial a partir do dever de eliminação da violência de gênero no mundo do trabalho? Partindo dessa delimitação, optou-se pela estratégia metodológica da revisão de literatura sobre teoria jurídica feminista e direitos humanos e da análise documental no sistema internacional de direitos humanos. Dois foram os resultados principais: a) o conteúdo da Convenção 190 da OIT deve ser interpretado como parte do sistema internacional de direitos humanos e da incorporação da categoria analítica gênero no campo normativo; b) o julgamento com perspectiva de gênero é um dever para os Estados-partes do Sistema Interamericano de Direitos Humanos (SIDH) e suas possíveis contribuições para a proteção contra a violência de gênero laboral no Brasil é um tema a ser desenvolvido.
\end{abstract}

Palavras-chave:

Violência de gênero. Direito do Trabalho. Acesso à Justiça

\begin{abstract}
:
The article analyzes the state duty to eliminate the violence at work and its articulation with judging in a gender perspective on labor issues. This approach was selected because it allows understanding the evolution of theoretical and normative production on gender, work and violence and the interface between labor law and human rights. Therefore, its elaboration had a structural question: How Convention 190 of the International Labor Organization (ILO) could contribute to the transformation of the theory of judicial decision. Starting from this delimitation, we opted for the methodological strategy of literature review in feminist legal theory and human rights and documentary analysis in the international human rights system. There were two main results: a) to understand the content of ILO Convention 190 as part of the international human rights system and the incorporation of the analytical category gender; b) to establish that gender-based judging is a duty for States parties to the Inter-American Human Rights System (ISHR) and to explore their possible contributions to protection against gender-based violence in Brazil.
\end{abstract}

Keywords:

Gender violence. Labor Law. Access to justice

\footnotetext{
${ }^{1}$ Doutora em Direito do Trabalho e da Seguridade Social pela Faculdade de Direito da Universidade de São Paulo. Mestre em Direito Negocial pela Universidade Estadual de Londrina. Bacharel em Direito pela Universidade Estadual de Maringá. Professora Adjunta do Curso de Direito da Universidade Estadual do Oeste do Paraná. Email: carolina.kemmelmeier@unioeste.br

2 Doutora e Mestra em Direito do Trabalho e da Seguridade Social pela Faculdade de Direito da Universidade de São Paulo. Graduada em Direito pela Faculdade de Direito de Ribeirão Preto da Universidade de São Paulo. Advogada. Professora na Escola de Direito de São Paulo da Fundação Getúlio Vargas. Pesquisadora sênior do Centro de Ensino e Pesquisa em Inovação da Fundação Getúlio Vargas. Atualmente realiza Pós-doutorado com apoio do CNPq na Universidade de São Paulo. E-mail: olivia.pasqualeto@fgv.br
} 


\section{INTRODUÇÃO}

O direito a um meio ambiente laboral livre de violência e sua articulação com o julgamento em perspectiva de gênero na esfera trabalhista é o tema deste artigo.

A violência de gênero, enquanto categoria conceitual, tem como pressuposto a dimensão estrutural de discursos e práticas na sociedade que atribuem ao feminino uma posição de inferioridade ou de capacidade reduzida. Com isso, há a construção de estereótipos que podem legitimar, naturalizar e ocultar violências. Nesse artigo, em razão de recorte temático, a análise se dedica primordialmente à violência de gênero nas relações de trabalho em relação às mulheres, embora não se ignore que essa seja uma questão de alto impacto também para a população LGBTQIA+.

Esse enfoque foi escolhido por permitir contextualizar e compreender a evolução do debate sobre gênero, trabalho e violência, bem como a interface entre direito do trabalho e direitos humanos, especialmente no que diz respeito à interpretação do direito à não discriminação. A pergunta estruturante para seu desenvolvimento foi a seguinte: quais são as potenciais contribuições da Convenção 190 da Organização Internacional do Trabalho (OIT) para a transformação da teoria da decisão judicial a partir da afirmação do dever de eliminação da violência de gênero no mundo do trabalho?

A indagação central deste artigo resulta da constatação de que a violência contra mulheres é uma das violações mais recorrentes de direitos humanos, problema esse que se tornou ainda mais visível após a epidemia de COVID-19. E mais, evidências coletadas entre 2019 e 2020 indicam que o assédio sexual no ambiente de trabalho afeta aproximadamente metade das mulheres no Brasil ao longo de sua trajetória profissional. A mudança dessa realidade requer transformações significativas na cultura, inclusive jurídica, sobre a violência no mundo do trabalho e sobre como homens e mulheres vivenciam e são impactados de forma distinta por ela, inclusive quando apresentam suas demandas perante o Poder Judiciário.

Partindo dessa delimitação, optou-se pela estratégia metodológica da revisão de literatura no campo da teoria jurídica feminista e dos direitos humanos e da análise documental no âmbito do sistema internacional de direitos humanos.

O desenvolvimento do texto foi estruturado em três eixos. O primeiro deles aborda a interface entre Direito do Trabalho, gênero e teoria jurídica feminista e se desenvolve de modo a identificar a origem e as articulações existentes entre esses elementos.

O segundo segmento contextualiza a violência de gênero em uma perspectiva normativa de modo a compreender a sua inserção no conteúdo da Convenção 190 da OIT. 
A parte final, por sua vez, tem como foco analisar o julgamento com perspectiva de gênero como um dever para os Estados-partes do Sistema Interamericano de Direitos Humanos (SIDH) e explorar suas possíveis contribuições para a proteção contra a violência de gênero laboral no Brasil.

Espera-se que essa análise, em caráter exploratório, possa contribuir para o desenvolvimento de futuras pesquisas quanto às potencialidades do feminismo jurídico e do julgamento com perspectiva de gênero para a transformação da cultura jurídica de proteção das mulheres e das pessoas LGBTQIA + no mundo do trabalho.

\section{AS LENTES DE GÊNERO, A TEORIA FEMINISTA DO DIREITO E O DIREITO DO TRABALHO}

O sistema internacional de direitos humanos, especialmente no que diz respeito ao tema da igualdade, adota o gênero como uma categoria de análise central para dar visibilidade às relações de poder e dominação e identificar diferenciações que foram e são socialmente construídas e, portanto, não são inatas ou naturais às pessoas (CEDAW, 2015, p.4).

O Comitê criado a partir da Convenção sobre a Eliminação de Todas as Formas de Discriminação contra as Mulheres, conhecida por sua sigla em inglês, CEDAW (2010, p. 2) esclarece que a proibição de discriminação, prevista na referida convenção, compreende aquelas fundamentadas no sexo e no gênero. A expressão sexo se refere às diferenças biológicas entre homens e mulheres. O gênero, por sua vez, abarca as identidades, atributos e papéis distintos atribuídos aos homens e mulheres e que são socialmente construídos. As relações de poder e subordinação associada ao gênero estão presentes em todas as sociedades e resultam em uma distribuição desigual de poder e oportunidades que favorecem os homens e prejudicam mulheres e pessoas que não se encaixam nos padrões de gênero, como a população LGBTQIA+

A teoria feminista do direito, por sua vez, designa construções teóricas e movimentos emancipatórios constituídos por matrizes filosóficas diversas, como a liberal, anarquista, marxista, ecofeminista, pós-colonial, que incidem sobre a forma de pensar, de ensinar, de criar e interpretar e de viver o direito. O feminismo jurídico, portanto, abrange áreas, como a teoria e filosofia do direito, dogmática jurídica, teorias da interpretação e decisão judicial, educação jurídica e produção normativa (LERUSSI, 2020).

A construção da teoria feminista do direito é atribuída à sinergia de ações no campo acadêmico e profissional do Direito nos EUA a partir da década de 1970 sob o termo Feminism Legal Studies. Na América Latina, esse campo apresenta singularidades associadas 
às culturas jurídicas desse território e às interseccionalidades entre movimentos feministas, de direitos humanos e da comunidade LGBTQIA+ (COSTA; LERUSSI, 2017; BERGER; CRAWFORD; STANCHI, 2018).

É possível identificar na pluralidade dos feminismos jurídicos dois pressupostos compartilhados: a) mulheres e pessoas LGBTQIA+ são subvalorizadas pelo Direito; b) essa cultura jurídica de subvalorização tem origem no domínio masculino, produtor de desigualdades múltiplas e estruturais e raiz de uma série de violências (LERUSSI, 2020).

Esses pressupostos atuam diretamente sobre o campo jurídico, uma vez que reconhecem a articulação do dualismo simbólico entre masculino e feminino; a hierarquização do primeiro sobre o segundo e, finalmente, a identificação do direito com simbolismo masculino, ou seja, com a racionalidade, a objetividade/neutralidade, a abstração, o poder (OLSEN, 1990)

A divisão sexual do trabalho, parte integrante desse dualismo simbólico, atribuiu aos homens o exercício de atividades voltadas para a produção e, às mulheres, o desempenho de tarefas de cuidado e uma tradição de submissão aos homens. A inserção das mulheres no mercado de trabalho com o capitalismo, portanto, se desenvolve em meio a esses estereótipos de gênero e expõe as trabalhadoras a riscos aumentados de discriminação e de violência no mundo do trabalho, o que afeta sua empregabilidade, suas oportunidades de crescimento profissional e sua saúde (LLOYD; TALUC, 1999).

A interface entre o trabalho, gênero e direito é objeto da teoria feminista jurídica em sua dimensão teórica e técnica. Para tanto, o ponto de partida está em considerar que o Direito do Trabalho foi historicamente constituído - ainda que parcialmente - como um ordenamento jurídico garantista, ou seja, voltado para a proteção dos trabalhadores em função de sua vulnerabilidade frente ao poder patronal. Retomar essa origem com os referenciais do feminismo jurídico reposiciona o questionamento sobre quem é abrangido e quem é excluído da proteção jurídica do Direito do Trabalho e sobre o que se entende por vulnerabilidade (LERUSSI, 2020, p. 11-12).

Um aporte central dessa indagação é reconhecer e dimensionar como a relação de poder é duplicada para as mulheres e pessoas LGBTQIA+ no mundo do trabalho frente à articulação entre a subordinação de classe vivenciada pelos trabalhadores no capitalismo com a dinâmica da subvalorização feminina nas sociedades patriarcais. Desse modo, incluir a dimensão de gênero como categoria analítica de normas jurídicas e o feminismo jurídico enquanto referencial teórico permite se distanciar da ficção normativa universalizante que tem como pressuposto um empregado homem, branco, maior de idade e heterossexual, bem como da 
limitação da caracterização restritiva de trabalho como a prestação de serviços remunerada no setor produtivo em sentido estrito. (VIEIRA, 2015; LERUSSI, 2020).

Essa expansão passa pelo reconhecimento jurídico do trabalho reprodutivo não remunerado e de suas articulações com o trabalho produtivo, da divisão sexual do trabalho como origem de preconceitos e estereótipos que incidem sobre o campo jurídico no plano normativo e interpretativo e, consequentemente, sobre como o ordenamento jurídico e as instituições de justiça atuam de modo desproporcional sobre o acesso aos direitos das mulheres.

Inclui-se, igualmente, a revisão dos bens jurídicos e das garantias que devem compor Direito do Trabalho, de modo a repensar o direito à saúde, o direito à vida privada e a delimitação de tempos de trabalho e de não-trabalho com o avanço das novas tecnologias e mecanismos de vigilância e seus diferentes impactos em uma perspectiva de gênero, bem como as possiblidades de proteção no setor doméstico, de cuidados, do trabalho sexual, do trabalho em domicílio e do teletrabalho de modo a considerar as interseccionalidades em matéria de divisão sexual, racial, étnica e migratória do trabalho (LERUSSI, 2020, p. 22).

Na América Latina, o desenvolvimento da teoria feminista do Direito do Trabalho é especialmente relevante uma vez que as mulheres são mais afetadas pelo desemprego, trabalho precário e informalidade e se encontram em maior proporção em situação de pobreza (CEPAL, 2016). Esse cenário de vulnerabilidade se agravou em 2020 diante da crise associada ao Covid19 e seus impactos em matéria de fechamentos de postos de trabalho em setores com alta ocupação feminina (comércio, restaurantes, hotéis e serviços domésticos) e da saída de mulheres do mercado de trabalho em razão das responsabilidades adicionais com o cuidado de crianças e idosos decorrentes dos desdobramentos da pandemia (CEPAL, OIT, 2020).

Pela perspectiva do rendimento e da formação (ensino médio e ensino superior) no Brasil, os rendimentos de homens brancos são superiores aos das mulheres, sendo que entre a população com ensino superior, os homens brancos têm média remuneratória $159 \%$ superior às mulheres negras com o mesmo nível de formação (RIBEIRO; KOMATSU; MENEZESFILHO, 2020). Essa significativa desigualdade salarial no Brasil é confirmada pela constatação de que, ainda que em idêntica ocupação, os homens brancos recebem os maiores salários e, inversamente, as mulheres negras, os menores. (OXFAM BRASIL, 2018; OXFAM BRASIL, 2019).

Segundo a Comissão Interamericana de Direitos Humanos (CIDH), as ofensas de direitos humanos vivenciadas pelas mulheres em sua atuação profissional decorrem de fatores como: a discriminação e violência de gênero nas sociedades, a qual é reproduzida no ambiente laboral; o desequilíbrio de poder entre atores empresariais e mulheres e da omissão dos Estados 
para a proteção e promoção dos direitos nessa área. E destaca: "Isto se agrava quando estas práticas e comportamentos fazem parte de um contexto social, político e normativo patriarchal que o sustém e oculta, como por exemplo, minando seus direitos a condições laborais justas e equitativas em comparação com os homens ${ }^{3}[\ldots]$ ”. (CIDH, 2020).

Dentre as variadas violações aos direitos humanos no mundo do trabalho, essa pesquisa foca a violência de gênero, as inovações no campo do direito internacional dos direitos humanos e seus desdobramentos sobre o acesso à justiça e a atuação do Poder Judiciário.

\section{A VIOLÊNCIA DE GÊNERO E O MUNDO DO TRABALHO}

O campo jurídico, em um primeiro momento, compreendia a violência contra as mulheres como o comportamento (individual) desviante de certos indivíduos e como parte de culturas primitivas.

A violência de gênero, enquanto categoria conceitual, substitui essa leitura ao atribuir uma dimensão estrutural e multifatorial a esse fenômeno, consubstanciada em discursos e práticas que permeiam instituições sociais, econômicas e culturais de modo a enquadrar o feminino em uma posição de inferioridade ou de capacidade reduzida e a construir estereótipos quanto aos comportamentos desejados em uma "verdadeira masculinidade e feminilidade" (HOTMAAT, 2008). Essas características, notadamente os padrões e estereótipos associados ao gênero e o desequilíbrio de poder, tendem a legitimar, naturalizar e ocultar essa violência

No sistema internacional de proteção dos direitos humanos, a Convenção de Belém do Pará foi o primeiro instrumento internacional a afirmar expressamente o direito a uma vida livre de violência de gênero, inclusive do assédio sexual no trabalho, diante da relação direta desta com o impedimento e anulação dos direitos humanos de mulheres e a estabelecer deveres estatais de proibição e prevenção para a eliminação da violência de gênero (OEA, 1994).

No âmbito da Organização das Nações Unidas (ONU), a violência de gênero foi caracterizada na Convenção de Beijing como "qualquer ato que, seja na vida pública ou privada, resulte ou possa resultar em dano ou sofrimento físico, sexual ou psíquico, incluindo ameaça, coerção ou privação de liberdade" (ONU, 1995).

A partir desse referencial, a Corte Interamericana de Direitos Humanos afirmou a obrigação do Estado de proteção e responsabilização internacional inclui a prática de atos de

\footnotetext{
${ }^{3}$ Trecho original: "Esto se agrava cuando tales prácticas y comportamientos hacen parte de un contexto social, político y normativo patriarcal que lo sostiene y oculta, por ejemplo, socavando su derecho a condiciones laborales justas y equitativas en comparación con los hombres
} 
atos privados, inclusive aqueles que sejam desdobramentos das atividades empresariais sobre esse tema, notadamente no mundo do trabalho (CIDH, 2020).

Quanto a sua prevalência, a revisão de literatura indica que a violência de gênero se manifesta em todos os setores da sociedade, independentemente de classe, raça, nível educacional, idade ou religião e compreende distintas modalidades como a física, psicológica, sexual e econômica (OEA, 1994).

Aproximadamente 235 milhões de mulheres, em 59 países, trabalham sem normas jurídicas proibindo o assédio sexual. A América Latina representa $33.3 \%$ desse universo de países (BANCO MUNDIAL, 2018, p. 20).

A existência de um quadro jurídico interno, entretanto, não é garantia de eliminação dessa violação, como ilustra o caso brasileiro, uma vez que metade das mulheres brasileiras foram vítimas de assédio sexual no ambiente laboral durante sua trajetória profissional (THINK EVA, 2020). As condutas vivenciadas foram: solicitação de favores sexuais (92\%); contato físico não solicitado (91\%) e abuso sexual (60\%). Essa violência é aumentada quando as entrevistadas são mulheres negras ou têm remuneração entre dois e seis salários mínimos, ou seja, raça e classe são fatores agravantes. (THINK EVA, 2020).

A alta ocorrência do assédio sexual, manifestação mais perceptível da violência vivenciada por mulheres meio ambiente de trabalho, dialoga com constatação de que a violência de gênero é a violação de direitos humanos mais prevalente em termos mundiais (UNDURRAGA, NORKICKEL, 2020). A violência no mundo do trabalho, portanto, não é a mesma para homens e mulheres.

O debate sobre a violência de gênero, teoria feminista do direito e o Direito do Trabalho encontra um novo marco em 2019 com a aprovação da Convenção 190 da Organização Internacional do Trabalho (OIT), a qual inova em matéria a proteção em matéria de violência de gênero em relação à CEDAW e à Convenção de Belém do Pará.

Um primeiro elemento de aperfeiçoamento é a caracterização da violência, isso porque se refere à violência laboral como comportamentos e práticas inaceitáveis, inclusive ameaças, sejam estes atos únicos ou repetidos, que tenham por objetivo, resultem ou que possam resultar em dano físico, psíquico, sexual ou econômico. E mais, considera-se que essa será caracterizada como violência de gênero quando tenham como motivação o sexo ou gênero ou quando afetem pessoas de um determinado sexo ou gênero desproporcionalmente (art. 1).

Essa delimitação é inovadora por não restringir o conceito de violência laboral, inclusive a de gênero, à uma conduta intencional do agente, seja de causar dano, seja de discriminar em 
razão de gênero, o que contribui para a tipificação jurídica e pode diminuir a dificuldade de produção de provas (DESIERTO, 2019).

A terminologia violência e assédio baseado em gênero compreende, portanto, toda ação, comportamento ou prática institucional que implique em abuso, desmerecimento e preconceito contra uma pessoa com base no gênero e que ocorra no mundo do trabalho. Essas práticas hostis abrangem abusos que têm como fundamento o que se espera em termos de conduta e personalidade das mulheres e homens em uma determinada sociedade e em um específico contexto. Integram essa categoria, além do assédio sexual, práticas como o assédio ambiental, a discriminação em razão da maternidade e o tratamento condescendente (UNDURRAGA, NORKICKEL, 2020).

Esse marco regulatório da Convenção 190 avança da cobertura subjetiva ao estabelecer sua incidência para todas as relações laborais, inclusive aquelas no setor informal ou com contratos atípicos, campo esse prevalentemente feminino na maioria dos países (CEPAL, 2016; OIT, 2018). Aqui se mostra o potencial de transformação do feminismo jurídico sobre os padrões internacionais de proteção do trabalho.

O parâmetro de proteção devido pelo Estado e pelos empregadores foi também alterado. Não se trata mais de uma atuação de reação, individualizada e caso a caso. Agora o referencial é de prevenção ativa (due diligence), com o dever de criar políticas públicas e condições de trabalho que identifiquem os riscos e atuem na sua eliminação e, sucessivamente, mitigação (DESIERTO, 2019).

Há, portanto, a adoção da tolerância zero em matéria de violência no mundo do trabalho, ou seja, da desnaturalização da violência como parte inerente das relações de trabalho, inclusive daquela que tenha como fundamento direto ou indireto uma cultura patriarcal. (art. 4, 1). Para tanto, os Estados têm o dever de construir e implementar, com base no diálogo social, uma metodologia de ação inclusiva, sistemática e que leve em consideração a questão de gênero. Essa deve ser estruturada por medidas legislativas, políticas públicas, mecanismos de monitoramento, fiscalização e reparação, bem como ações educativas em toda a sociedade. (Convenção 190, art. 4, 2 e art. 2 da Recomendação 206).

Além disso, há o dever estatal de construção de um quadro jurídico nacional que atribua aos empregadores e tomadores de serviços o dever de uma política corporativa para a prevenção da violência no mundo do trabalho que integre a perspectiva de gênero. Essa política interna tem como elementos estruturantes a identificação, avaliação e monitoramento dos riscos de violência laboral de modo integrado com a gestão dos riscos à segurança e saúde do trabalho, 
bem como a capacitação e treinamento das pessoas para uma cultura organizacional de zero tolerância quanto à violência no mundo do trabalho (art. 9 da Convenção 190).

A Recomendação 206 da OIT esclarece que as medidas empresariais devem ser construídas por meio de objetivos mensuráveis; da atribuição de direitos e responsabilidades nos códigos de conduta e regulamentos de empresa; da inclusão de informações acessíveis e claras sobre os procedimentos para a apresentação de denúncias e sobre como será conduzida a investigação, com garantias quanto ao direito à privacidade e confidencialidade e adoção de providências para proteção das vítimas, testemunhas e denunciantes contra a retaliação e vitimização (art. 7 da Recomendação 206).

Um aspecto a ser analisado com profundidade nas inovações presentes na Convenção 190 da OIT é a inserção, no âmbito dos deveres estatais, do acesso à justiça e do papel desempenhado pelo julgamento com uma perspectiva de gênero para a proteção dos direitos humanos.

\section{O ACESSO À JUSTIÇA E O JULGAMENTO COMO PERSPECTIVA DE GÊNERO NO MUNDO DO TRABALHO}

A Convenção 190 da OIT insere, no âmbito dos deveres estatais, o acesso à justiça em sua acepção material ao se referir à implantação de mecanismos de solução de controvérsias que sejam seguros, efetivos e que adotem a perspectiva de gênero (art. 10, e), bem como que as autoridades recebam capacitação, treinamento e recursos para atuar em matéria de violência de gênero (art. 11, b).

A Recomendação 206 da OIT esclarece que esses mecanismos de solução de controvérsias relativos à violência de gênero devem incluir medidas como julgadores qualificados e especializados para a atuação nessa área, procedimentos eficientes e rápidos e possibilidade de inversão do ônus da prova (art. 16).

Essas previsões dialogam com as Recomendações Gerais da CEDAW, especialmente a Recomendação n. 33, e com os parâmetros firmados no âmbito do Sistema Interamericano de Direitos Humanos (SIDH).

A discriminação estrutural em matéria de gênero afeta o acesso à justiça em virtude de uma série de obstáculos decorrentes de leis discriminatórias, estereótipos de gênero, discriminação intersecional, procedimentos e práticas em matéria probatória e barreiras econômicas, sociais e culturais de acessibilidade à administração da justiça por parte das 
mulheres e das pessoas LGBTQIA+. Esse conjunto de limitações podem ser caracterizadas como persistentes violações de direitos humanos (CEDAW, 2015, p. 3).

No âmbito do SIDH a mesma racionalidade é observada na Convenção de Belém do Pará, uma vez que essa aborda especificamente a relação entre atividade jurisdicional e eliminação da violência de gênero (art. 7 e 8).

Dentro do universo do acesso à justiça e gênero, essa pesquisa dirige a atenção para o desenvolvimento do conceito e práticas de julgamento com perspectiva de gênero. A perspectiva de gênero é conceituada como uma ferramenta de análise necessária para superar a estereotipação judicial, ou seja, os preconceitos, estereótipos e papéis de gênero que legitimam a aplicação e interpretação das normas jurídicas em descompasso com os parâmetros do sistema internacional de direitos humanos, a apuração dos fatos e a valoração das provas de modo a perpetuar a discriminação e desigualdade em matéria de gênero e outras violações de direitos humanos. Sua implementação possibilita o enfrentamento de deficiências dos sistemas de justiça, mais precisamente, a falta de formação dos profissionais dos sistemas de justiça quanto a esse tema e os julgamentos insensíveis a questões de gênero (CEDAW, 2015)

As obrigações previstas na Convenção de Belém de Pará e a interpretação construída pela Corte Interamericana de Direitos Humanos (Corte IDH) quanto a essa figura vinculam os Estados-partes e os profissionais que atuam na administração da justiça nacionais (MÉXICO, 2020)

A revisão de literatura feita identificou que Bolívia (2017), México (2020) e Uruguai (2020) adotaram protocolos ou guias sobre o tema. A partir das decisões da Corte IDH, é possível identificar os seguintes elementos a serem integrados em um julgamento com perspectiva de gênero: a) análise do contexto social, político e cultural do caso; b) apreciação dos fatos; c) valoração das provas; d) verificação dos procedimentos adotadas durante a investigação administrativa; e) identificação dos distintos níveis de discriminação relacionados à interseccionalidade; f) identificação de preconceitos e estereótipos de gênero; g) fixação de medidas de reparação. (MÉXICO, p. 103).

Uma etapa preparatória e fundamental para a transformação da cultura jurídica em matéria de decisão judicial e acesso à justiça é a educação em uma perspectiva de gênero dos profissionais do sistema de justiça e estudantes de direito, especialmente para a sensibilização quanto aos problemas associados aos estereótipos e preconceitos de gênero e seus desdobramentos em cada área do sistema de justiça (CEDAW, 2015, p. 15). Tal etapa torna-se ainda mais relevante ao se observar a composição do Poder Judiciário brasileiro. Embora a participação feminina seja maior na magistratura trabalhista, representando cerca de 49,4\% 
(CNJ, 2019), o Poder Judiciário brasileiro é composto "em maioria por magistrados do sexo masculino, com apenas 38,8\% de magistradas em atividade" (CNJ, 2019, p. 7). A porcentagem é ainda menor ao analisar a composição dos tribunais. De acordo com dados do Conselho Nacional de Justiça, apenas $25,7 \%$ dos cargos de desembargadores são ocupados por magistradas (CNJ, 2019).

Inclui-se nesse processo a formação sobre o sistema internacional e regional de proteção de direitos humanos, suas recomendações e seus desdobramentos sobre o processo de decisão judicial em matéria de gênero, seja porque os parâmetros construídos no SIDH devem orientar a interpretação das normas internas de cada Estado Parte, inclusive pela magistratura, seja porque norma estatal deve ser afastada em caso de incompatibilidade com o SIDH por meio do controle de convencionalidade (GUEDES, 2016; BOLÍVIA, 2017).

O desenvolvimento continuado desta fase educativa compreende ainda a realização de estudos quantitativos e qualitativos, com participação de organizações da sociedade civil e da academia, incorporando o referencial das análises de gênero e do feminismo jurídico, de modo a identificar e disseminar práticas e jurisprudência que impactem, de modo positivo e negativo, sobre o pleno acesso à justiça (CEDAW, 2015, p. 11).

Sobre o processo decisório em si, as estruturas adotadas pelos protocolos e guias analisados, apesar de suas diferenças, adotam uma estrutura comum composta pelas seguintes etapas a) análise do ordenamento jurídico estatal de modo a identificar as normas jurídicas aplicáveis e possíveis problemas de discriminação normativa em matéria de gênero (controle de constitucionalidade, controle de convencionalidade, interpretação conforme a constituição; b) análise dos fatos e argumentos trazidos pelas partes de modo a não perpetuar estereótipos e preconceitos de gênero, tais como a crença em comportamentos apropriados para homens e mulheres ou menor valoração dos depoimentos de mulheres ou pessoas LGBTQIA+ c) fixação de medidas reparatórias que sejam apropriados para eliminar, prevenir e reparar a discriminação e violência de gênero, com atenção especial para a reparação integral do dano sofrido contemplando, na medida do possível, medidas de: restabelecimento, compensação (monetária e em bens e serviços), reabilitação (serviços de atenção à saúde e serviços sociais). (CEDAW, 2015, p. 9; BOLÍVIA, 2017; MÉXICO, 2020; URUGUAI, 2020)

As áreas específicas do direito analisadas no sistema internacional de direitos humanos e nos protocolos e guias estatais sobre o julgamento na perspectiva de gênero são, preponderantemente, o direito penal e o direito de família. Em termos laborais, embora não sejam apresentados exemplos de decisões com perspectiva de gênero, há a indicação da 
discriminação normativa no caso de normas que proíbam certos trabalhos a mulheres, como trabalho noturno e trabalho com armas de fogo (MÉXICO, 2020; URUGUAI, 2020)

Constata-se, portanto, a necessidade de desenvolvimento teórico e prático na área do Direito do Trabalho e do julgamento em perspectiva de gênero. Um caminho possível para tanto é a estratégia adotada pelo Feminism Legal Studies de realização de eventos e redes de pesquisa para o diálogo entre academia, profissionais do direito, notadamente aqueles que atuam em uma perspectiva de defesa de mulheres e outros grupos vulneráveis, organizações da sociedade civil e profissionais do sistema judiciário (BERGER; CRAWFORD; STANCHI, 2018).

Em termos de assuntos a serem explorados, há demanda pelo desenvolvimento de suporte teórico para decisões em perspectiva de gênero que contemplem: a) a distribuição do ônus probatório e valoração da prova em casos de assédio sexual no trabalho; b) o papel dos estereótipos de gênero no enquadramento de condutas assediadoras como "galanteios naturais inerentes ao ambiente de trabalho" (TRT $8^{a}$ Região, 2015); c) a possibilidade de caracterização de práticas assediadoras e discriminatórias de gênero como dano in re ipsa diante de seu caráter de violação de direitos humanos; d) a presunção relativa de despedida discriminatória para mulheres nos primeiros anos após a maternidade e após a denúncia de violência laboral; e) a admissibilidade de prova estatística, em uma perspectiva de gênero, nos casos de discriminação na contratação, promoção e remuneração; f) os limites ao uso da inteligência artificial para a seleção e avaliação de trabalhadores diante da possibilidade de discriminação algorítmica fundada em gênero.

Os desdobramentos do julgamento trabalhista com perspectiva de gênero são exemplificados em um acórdão do TRT da 4a. Região, o qual inverte o ônus probatório na extinção contratual por justa causa fundada em prática de assédio sexual. Assim, caberia ao agressor comprovar a existência de justificativa para a diferença de tratamento entre homens e mulheres no ambiente de trabalho. E além da dimensão probatória, a perspectiva de gênero se mostra também na fixação da reparação, ao consignar que a demissão por justa causa deve ser acompanhada, como parte da due diligence empresarial, por medidas educativas de modo a evitar a repetição de discriminação e violência de gênero nas relações de trabalho (BRASIL, 2020a).

A perspectiva de gênero também foi adotada em acórdão do TRT da 15a. Região para, com fundamento na Convenção de Belém do Pará e da CEDAW, aumentar o valor da condenação por assédio moral contra empregada, uma vez que se tratava de comportamento misógino e ofensivo a toda a coletividade: 
O comportamento sexual inadequado é o principal instrumento de ofensas às mulheres, notadamente em razão da padronização de mecanismos de insultos que são mantidos em razão de uma cultura de passividade, mansidão, que é imposta às mulheres, que devem sofrer "caladas". Adjetivações como "puta", "vadia", "louca" e semelhantes fazem parte de um vocabulário socialmente aceito como forma de vincular essas ações a atos tipicamente femininos. A partir disso, a expressão "biscate", caso dos autos, é utilizada como meio para ofender a mulher, que deve "sofrer calada" para não ser objeto de agressão física. O mesmo acontece com o termo "vadia" que é utilizado para oprimir a sexualidade das mulheres, tornando-as um mero objeto de satisfação sexual (BRASIL, 2020b).

Considerando a prevalência das mulheres em relações de emprego atípicas (como a terceirização), no setor informal e no setor de trabalho doméstico, também merece ser investigado como o estímulo à conciliação, por meio da celebração de transações judiciais sem reconhecimento de vínculo empregatício com o tomador dos serviços e com considerável redução do valor devido possa se configurar como um mecanismo de legitimação da violação de direitos humanos no meio ambiente de trabalho para esses setores pela falta de uma reparação integral e pelo desproporcional impacto que teria sobre as trabalhadoras.

A incorporação do conceito de due diligence e seus desdobramentos sobre os deveres dos empregadores e sua responsabilização jurídica igualmente pode ser contemplada por meio da perspectiva de gênero nas decisões judiciais. Os deveres jurídicos de respeito, proteção e promoção que decorrem dos direitos humanos no Direito Internacional não se destinam apenas aos Estados, mas também a atores não-estatais, como as empresas, inclusive em temas afetos ao Direito do Trabalho. Conforme salienta Cardia (2014), embora as empresas não tenham legitimidade para celebrar tratados internacionais no sentido formal, "não é mais possível negar a importância material dos acordos celebrados entre as empresas transnacionais e os Estados no plano global" (CARDIA, 2014, p. 40).

A concepção de responsabilidade empresarial e dever de prevenção associada à due diligence em direitos humanos foi uma influência significativa na estruturação da Convenção 190 da OIT e, portanto, poderão ser aplicadas nas decisões em matéria de violência em razão de gênero. Sobre o caráter mandatório da due diligence em matéria de violência laboral, relembra-se, conforme exposto no item 2 deste artigo, que a Convenção determina que os Estados construam um marco regulatório em que as organizações produtivas tenham o dever de adotar medidas preventivas por meio de uma política corporativa constituída pela identificação, avaliação e monitoramento contínuo dos riscos de violência laboral (OIT, 2019, artigo 9).

O julgamento em uma perspectiva de gênero no campo do Direito do Trabalho torna possível avançar na interpretação e solução de conflitos das normas jurídicas laborais por meio 
do referencial teórico dos direitos humanos. Desse modo, afasta-se do paradoxo lamentável segundo o qual "o movimento dos direitos humanos e o movimento trabalhista correm em trilhas que às vezes são paralelas e raramente se encontram" (LEARY, 1996, p.22).

Os core labour rights da Declaração sobre Princípios e Direitos Fundamentais do Trabalho (OIT, 1998) e o desenvolvimento do conceito de trabalho decente, além de representar uma mudança na estratégia regulatória da OIT, se destacou por levar ao reconhecimento expresso destes como direitos humanos na ONU (FUDGE, 2007; BELLACE, TER HAR, 2019). Esse enquadramento, o qual inclui o direito a não-discriminação e o direito à saúde como elementos do trabalho decente, protege seu conteúdo frente a questionamentos econômicos e políticos (FUDGE, 2007; GOMES, 2014, p.29), já que os direitos humanos são mais dificilmente confrontados quando comparados com direitos trabalhistas, pois estes, muitas vezes, são tidos como custos que tendencialmente oneram os empregadores e, portanto, o mercado.

Assim, segundo Gomes (2014), ao identificar os core labour rights como direitos humanos é reforçada a universalidade e se sinaliza que esses direitos - não discriminação, por exemplo - não são flexionáveis a depender do contexto, isto é, continuam dotados de fundamentalidade inclusive no âmbito do trabalho.

O reforço à identificação de certos direitos trabalhistas como direitos humanos, e da violência laboral como violência de gênero, portanto, parece ampliar estrategicamente a sua relevância em matéria de interpretação e decisão judicial, especialmente com o reconhecimento do dever de julgamento em perspectiva de gênero pelo SIDH.

\section{CONSIDERAÇÕES FINAIS}

Considerando a realidade de que a violência de gênero se apresenta em grandes índices na América Latina e no Brasil, inclusive no mundo do trabalho, a pesquisa se voltou para a fundamentação jurídica do dever estatal de eliminação dessa violência e sua articulação com o julgamento em perspectiva de gênero.

A Convenção 190 da OIT, ao se direcionar a um tema sensível e central quando se trata de violações de direitos humanos no ambiente de trabalho (assédio e violência), adota a perspectiva de gênero presente no sistema internacional de direitos humanos (ONU e SIDH) e se desvencilha do binarismo - empregados e não empregados - aspecto esse que contribui para romper com a abstração do empregado como sujeito universal e considera as particularidades de como as mulheres, em virtude da divisão sexual do trabalho e dos preconceitos e estereótipos 
de gênero, têm maior dificuldade para se inserirem no setor formal de trabalho na maioria dos países, sobretudo em ocupações mais vulneráveis na área do trabalho doméstico e do cuidado.

Ao estabelecer a obrigação dos Estados construírem um marco regulatório para definição do dever de as empresas adotarem uma política preventiva de identificação, avaliação e monitoramento dos riscos associados à violência laboral, inclusive na perspectiva de gênero, a Convenção 190 dá um passo no sentido de alterar uma lógica muito enraizada e transformar a cultura da voluntariedade em dever de prevenção, bem como, em não restringir o conceito de violência laboral à uma conduta intencional do agente, seja de causar dano, seja de discriminar em razão de gênero, o que contribui para a tipificação jurídica e pode diminuir a dificuldade de produção de provas.

Em matéria de acesso à justiça e seus desdobramentos sobre a decisão judicial, questão central para esse texto, a Convenção 190 se mostra em conformidade com o referencial adotado pela SIDH a respeito do dever de julgamento com perspectiva de gênero. Esse dever é pautado pela ideia chave de superar a estereotipação judicial e se desdobra na adoção e aprimoramento dos seguintes elementos: a) educação em perspectiva de gênero dos profissionais do sistema de justiça e estudantes de direito; b) análise do ordenamento jurídico nacional de modo a identificar hipóteses de discriminação normativa em matéria de gênero e desenvolvimento de soluções interpretativas por meio do controle de convencionalidade, controle de constitucionalidade e interpretação conforme a Constituição; c) análise fática, probatória e dos argumentos apresentados pelas partes de modo a afastar estereótipos, preconceitos de gênero e revitimização das vítimas; d) fixação de medidas reparatórias adequadas em perspectiva de gênero.

A pesquisa documental nos protocolos e guias adotados por Bolívia, México e Uruguai identificou que esses não contemplam de modo específico as violências de gênero no mundo do trabalho. Há demanda pelo desenvolvimento de suporte teórico e estratégico para essa área de modo a contemplar temas como: tipificação sem estereotipação judicial do assédio sexual e distribuição do ônus probatório em uma perspectiva de gênero; a classificação da violência de gênero como dano in re ipsa; presunção de despedida discriminatória para mulheres após a maternidade ou após a denúncia de violência laboral e o aprimoramento do acesso jurídico material das trabalhadoras em caso de relações de emprego atípicas, no setor informal e no trabalho doméstico, diante dos possíveis desdobramentos da cultura de conciliação da Justiça do Trabalho. Esse levantamento é provisório e merece ser aprofundado, inclusive com abertura para a violência de gênero e LGBTQIA+, pelo diálogo entre pesquisadoras e pesquisadores na 
área de gênero e direito do trabalho, das advogadas e advogados que atuam com pessoas vulneráveis e dos profissionais da administração da justiça.

\section{REFERÊNCIAS BIBLIOGRÁFICAS}

BANCO MUNDIAL. Woman, business and the law. Washington, 2018.

BELLACE, J. R.; ter HAAR, B. Perspectives on labour and human rights. Research Handbook on Labour, Business and Human Rights Law, Cheltenham, UK: Edward Elgar Publishing, 2019.

BERGER, L. L.; CRAWFORD, B. J.; STANCHI, K. M. Feminist Judging Matters: How Feminist Theory and Methods Affect The Process of Judgment. University of Baltimore Law Review, v. 47, p. 167-197, 2018.

BOLÍVIA. Protocolo para juzgar con perspectiva de gênero, 2. ed. Chuquisaca: Órgano Judicial - Comitê de Gênero, 2017. Disponível em: https://tsj.bo/publicaciones/protocolopara-juzgar-con-perspectiva-de-genero/. Acesso em 20 de mar. de 2021.

BRASIL. Tribunal Regional do Trabalho da 4a. Região. 8a. Turma. Recurso Ordinário 00202720-041.2018.5.04.0027. Relator Desembargador José Marcelo Felin D Ambroso. Porto Alegre, 08 de setembro de 2020a.

BRASIL. Tribunal Regional do Trabalho da 15a. Região. 11a. Camara. Recurso Ordinário 0010404-56.2017.5.15.0072. Relator Desembargador João Batista Martins Cesar. Campinas, 17 de junho de $2020 b$.

CARDIA, Ana Cláudia Ruy. Empresas, direitos humanos e gênero: desafios e perspectivas na proteção e na emancipação da mulher pelas empresas transnacionais. 2014. $198 \mathrm{f}$.

Dissertação (Mestrado em Direito) - Pontifícia Universidade Católica de São Paulo, São Paulo, 2014.

CEDAW. General Recommentdation n. 28, 2010. Disponível em: https://documents-ddsny.un.org/doc/UNDOC/GEN/G10/472/60/PDF/G1047260.pdf?OpenElement. Acesso em: 11 de fev. de 2021.

CEDAW. Recomendação n. 33 sobre o acesso das mulheres à justiça, 2015. Disponível em: https://www.cnj.jus.br/wp-content/uploads/2019/09/769f84bb4f9230f283050b7673aeb063.pdf. Acesso em 10 de mar. de 2021.

CEPAL, OIT. Coyuntura Laboral en América Latina y el Caribe: la dinámica laboral en una crisis de características inéditas: desafíos de política. Santiago, 2020. Disponível em: https://repositorio.cepal.org/handle/11362/46308.

CEPAL. Balance preliminar de las economías de América Latina y el Caribe 2016. 2016. Disponível em < https://www.cepal.org/es/publicaciones/40825-balance-preliminar-economias-america-latina-caribe-2016 > Acesso em 13 abr. 2021.

CIDH. Compendio sobre derechos laborales y sindicales: estándares interamericanos, 2020. Disponível em: http://www.oas.org/es/cidh/informes/pdfs/DerechosLaboralesSindicales-es.pdf. Acesso em 13 fev. 2021. 
CNJ. Diagnóstico da participação feminina no poder judiciário. 2019. Disponível em < https://www.cnj.jus.br/wp-content/uploads/2019/05/cae277dd017bb4d4457755febf5eed9f.pdf > Acesso em 13 abr. 2021.

COSTA, Malena; LERUSSI, Romina. Los feminismos jurídicos en la Argentina. Notas para pensar un campo emergente. Estudios Feministas 26, n.1, p. 1-13, 2017.

DESIERTO, Diane. The ESCR revolution continues: ILO Convention n. 190 and the elimination and harassment in the world of work. European Journal of International Law, 2019. Disponível em: https://www.ejiltalk.org/the-new-ilo-convention-no-190-on-the-elimination-of-violence-and-harassment-inthe-world-of-work/. Acesso em 15 de mar. de 2021.

FUDGE, Judy. The new discourse of labor rights: From social to fundamental rights. Comparative Labor Law \& Policy Journal, v. 29, 2007, p. 29-66.

GOMES, Ana Virgínia Moreira. A Declaração da OIT de 1988: história, mudanças e desafios. In: GOMES, Ana Virgínia Moreira; FREITAS JÚNIOR, Antonio Rodrigues de. A Declaração de 1988 da OIT sobre Princípios e Direitos Fundamentais no Trabalhoanálise do seu significado e efeitos. São Paulo: LTr, p. 19-38, 2014,

GUEDES, R. C. O. O conteúdo do direito de acesso à Justiça e do princípio do devido processo legal na jurisprudência interamericana de direitos humanos. In: Defensoria Pública Geral. Cadernos estratégicos: análise estratégica dos julgados da Corte Interamericana de Direitos Humanos. Rio de Janeiro: CEJUR, pp, 51-65, 2016.

HOLTMAAT, Rikki, 2008, Preventing Violence Against Women: The Due Diligence Standard With Respect to Banish Gendersterotyped on the Grounds of Article 5(a) of the CEDAW Convention. BENNINGER-BUDEL, Carin (ed). Due Diligence And Its Application To Protect Women From Violence. Martin Nijhoff Publishers, Leiden, p. 5390, 2008.

LEARY, Virginia. The paradox of workers' rights as human rights. In: COMPA, Lance A.; DIAMOND, Stephen F. (Orgs.) Human rights, labor rights and international trade. The University of Pennsylvania Press: Pennsylvania, p. 22-47, 1996.

LERUSSI, Romina. Contornos para una epistemologia feminista del derecho del trabajo. VIERIA, Regina Stela Corrêa; TRAMONTINA, Robinson (org.). Desafios presentes e futuros do direito do trabalho: buscas entre interseções por um novo alvorecer. Joaçaba: Ed. Unoesc, p. 11-26, 2020.

LLOYD, S.; TALUC, N. The effects of male violence on female employment. Violence Against Women, 5, 370-392, 1999.

MÉXICO. Protocolo para juzgar con perspectiva de gênero. Ciudad del México: Suprema Corte de Justicia de la Nación, 2020. Disponível em:

https://www.scjn.gob.mx/registro/sites/default/files/page/2020-02/protocolo_perspectiva_genero.pdf. Acesso em 20 de mar. de 2021.

OEA. Convenção interamericana para prevenir, punir e erradicar a violência contra a mulher (Convenção de Belém do Pará), 1994. Disponível em:

http://www.cidh.org/basicos/portugues/m.belem.do.para.htm. Acesso em 10 de feveriro de 2021. 
OIT. Women and men in the informal economy: a statistical picture. Genebra: OIT, 2018.

OLSEN, Elizabeth. The Sex of Law. KAIRYS, David The Politics of Law: A Progressive Critique. New York, Pantheon, p. 452-467, 1990.

ONU. Report of the Fourth World Conference on Women, Beijing 4-15 September, 1995. New York, NY: United Nations.

OXFAM BRASIL 2018. País estagnado. Disponível em: https://oxfam.org.br/um-retratodasdesigualdades-brasileiras/pais-estagnado/. Acesso em 31 de janeiro de 2020.

OXFAM BRASIL 2019. A distância que nos une. Disponível em:

https://oxfam.org.br/umretrato-das-desigualdades-brasileiras/a-distancia-que-nos-une/. Acesso em 31 de janeiro de 2020.

RIBEIRO, Beatriz Caroline; KOMATSU, Bruno Kawaoka; MENEZES-FILHO, Naercio. Diferenciais salariais por raça e gênero para formados em escolas públicas ou privadas. Policy Paper, n. 45. São Paulo, Insper, Jul. 2020. Disponível em < https://www.insper.edu.br/wpcontent/uploads/2020/07/Policy-Paper-45.pdf >

THINK EVA; LINKEDIN. O ciclo do assédio sexual no ambiente de trabalho. 2020.

Disponível em < https://thinkeva.com.br/pesquisas/assedio-no-contexto-do-mundo-corporativo/ >. Acesso em 31 de janeiro de 2020 .

TRT $8^{\text {a }}$. Região. Justiça do Trabalho nega indenizações por assédio sexual, danos morais e horas extras. Disponível em: https://www.trt13.jus.br/informe-se/noticias/2015/07/justica-do-trabalhonega-indenizacoes-por-assedio-sexual-danos-morais-e-horas-extras.

UNDURRAGA, Rosario; LOPEZ HORNICKEL, Natalia. Trayectorias Laborales de Mujeres y Violencia en el Trabajo: Una Cuestión de Género. Psykhe, Santiago , v. 29, n. 2, p. 1-14, dic. 2020 . Disponible en

$<$ https://scielo.conicyt.cl/scielo.php?script=sci_arttext\&pid=S0718-

$22282020000200105 \& \operatorname{lng}=$ es\&nrm=iso $>$. Acesso em 14 jan. 2021.

URUGUAI. Guía para el Poder Judicial sobre estereotipos de género y estándares internacionales sobre derechos de las mujeres, 2020. Disponível em:

https://www.gub.uy/sites/gubuy/files/inline-

files/Gu\%C3\%ADa\%20para\%20el\%20Poder\%20Judicial.pdf. Acesso em 20 de mar.

VIEIRA, Regina Estella. Trabalho das mulheres e feminismo: uma abordagem de gênero do Direito do Trabalho. In: KASHIURA JR., C. N. (org.). Para a crítica do direito: reflexão sobre teorias e práticas jurídicas. São Paulo: Ed. Outras expressões, p. 22-34, 2015.

Submissão em 15/04/2021 / Aceito em 26/05/2021 